\title{
Interference of Salmonella typhimurium Lipopolysaccharide on Performance and Biological Parameters of Broiler Chickens
}

\section{-Author(s)}

Rauber $\mathrm{RH}$

Perlin VJ"

Fin CD"

Mallmann AL"

Miranda DPII

Giacomini LZ"I

Nascimento VP do

Federal University of Rio Grande do Sul (UFRGS) - Porto Alegre/RS - Brazil.

" Federal University of Santa Maria (UFSM) Santa Maria/RS - Brazil.

III SAMITEC Institute - Santa Maria/RS - Brazil.

\section{ABSTRACT}

This study was conducted to determine the interference of Salmonella typhimurium lipopolysaccharide (sLPS) on the performance, biological parameters, and histological evaluations of 198 one-day-old male broiler chickens divided into three treatments according to sLPS dose $(0,250$, or $500 \mu \mathrm{g} / \mathrm{application/bird)}$ that was applied to the birds every other day, from 15 to 27 days of age. At the end of the experiment (28 days), significant effects were observed on body weight $(R=-0.17$ and $P=0.05)$, total cholesterol serum levels $(R=0.43$ and $p<0.01)$, phosphorus ( $R=0.53$ and $P<0.01)$, uric acid $(R=-0.38$ and $P<0.01)$, C-reactive protein $(R=0.68$ and $p<0.01)$, serum activity of aspartate aminotransferase $(R=0.39$ and $p<0.01)$ and alkaline phosphatase $(R=$ -0.39 and $p<0.01)$. According to these results, sLPS mainly affect broiler biological parameters, but also their live performance.

\section{INTRODUCTION}

Lipopolysaccharide (LPS or Endotoxin) is the main component of Gram-negative bacterial cell wall, covering approximately $40 \%$ of the bacterial surface. The specific structure of LPS is different among bacterial species. However, in general, they have very similar molecular structures and can be divided in: Lipid A, Inner Core, Outer Core, and O Antigen. This antigen is responsible for immunogenic responses, and it is also the most variable part, which can be used to differentiate bacterial serotypes. Lipid A is a lipid portion of LPS, non variable among bacterial species (or serotypes), and it is responsible for LPS's toxicity (Liebers et al., 2008; Tuin, 2007).

The bacterial LPS is one of the most powerful activators of the immune system, leading to a non-specific inflammatory response (Mueller et al., 2004; Luyendyk et al., 2002). The environment of a poultry house can be highly contaminated with LPS in suspension, since the contamination of the facilities with Gram-negative bacteria is very common (Fernandes, 2005). Nevertheless, the presence of Gramnegative bacteria in the intestinal tract and the use of anti-bacterial drugs can increase poultry exposure to LPS. Extensive research has been conducted to determine the effects of LPS exposure in humans (Liebers et at., 2008; Roth et al., 1997) and mammals (Mueller et al., 2004; Luyendyk et al., 2002; Barton et al., 2000; Roth et al., 1997). However, there are few studies on the effects of LPS on broiler performance using in vivo procedures and with different inoculation doses.

The aim of this study was to provide information about the effects of Salmonella typhimurium Lipopolysaccharide (sLPS) on the performance, biochemical parameters, and histological evaluation in broilers. 
Rauber RH, Perlin VJ, Fin CD,

Mallmann AL, Miranda DP,

Giacomini LZ, Nascimento VP do
Interference of Salmonella typhimurium Lipopolysaccharide on Performance and Biological Parameters of Broiler Chickens

\section{MATERIAL AND METHODS}

The experiment was conducted with the approval and according to the recommendations of the Ethics Committee on the Use of Animals on Research of the Federal University of Rio Grande do Sul under the process number 19847.

\section{Birds, facilities, and management}

This study was carried out using 198 one-day-old male Cobb broilers purchased from a local hatchery. The experiment was conducted at Instituto SAMITEC'S experimental poultry farm, in Santa Maria, RS, Brazil (geographic coordinates: $29^{\circ} 42^{\prime} 44^{\prime \prime}$ South and $53^{\circ} 38^{\prime} 25^{\prime \prime}$ West).

The facilities consisted of a $20-\mathrm{m}^{2}$ room, under fulltime air-conditioning and exhaustion to maintain the ideal environmental temperature and air quality for the birds, and a 24-h of light lighting program during the entire experiment. Birds were kept in 18 electricallyheated battery brooders, with wired floors from 1 to 28 days of age.

Feed and water were provided ad libitum, and the feed was formulated to provide the minimum levels (NRC, 1994) of crude protein (20.00\%), energy $(3,050 \mathrm{kcal} / \mathrm{g})$, calcium $(0.95 \%)$, phosphorus available $(0.48 \%)$, methionine $(0.39 \%)$, methionine+cystine $(0.74 \%)$, and lysine $(1.19 \%)$.

\section{Experimental design}

Birds were randomly divided into three completely randomized treatments with six replicates of 11 birds each, according to the dose of lipopolysaccharide applied as presented below:

Treatment 1: birds received $0.5 \mathrm{~mL}$ of sterile saline solution (control group);

Treatment 2: birds received $0.5 \mathrm{~mL}$ of a $500 \mu \mathrm{g} / \mathrm{mL}$ sLPS solution. This inoculation gave a total of $250 \mu \mathrm{g}$ of sLPS/bird per application;

Treatment 3: birds received $0.5 \mathrm{~mL}$ of a $1,000 \mu \mathrm{g} /$ $\mathrm{mL}$ sLPS solution. This inoculation gave a total of 500 $\mu \mathrm{g}$ of sLPS/bird per application.

\section{Lipopolysaccharide administration}

The Salmonella typhimurium lipopolysaccharide (sLPS) was purchased from Sigma USA (item L7261) and diluted in sterile saline solution to reach the desired concentration and dose per treatment. Each bird received $0.5 \mathrm{~mL}$ of its treatment solution every other day, starting on day 15 until day 27 (seven applications). The sLPS solution was administered to the birds using a variable-volume calibrated micropipette, disposing the solution into the crop.

The dose of sLPS used in this study was established as a fixed amount of sLPS/bird per application.

\section{Evaluated variables and laboratorial analyses}

All birds were weighed at the beginning and on 14 day of the experiment to determine the homogeneity of the groups, and at the end of the experiment for performance evaluation. Feed intake was also measured on days 14 and 28 of the experiment.

At the end of the experiment, birds were euthanized by cervical dislocation after $\mathrm{CO}_{2}$ desensitization, for blood and tissue collection. Blood samples (18 per treatment) were collected from the cervical veins (after desensitization), centrifuged and the serum was stored at $-20^{\circ} \mathrm{C}$ until analysis. Serum samples were analyzed for total plasma proteins (TPP), albumin $(A L B)$, total cholesterol (COL), triglycerides (TRI), calcium (Ca), phosphorus (P), uric acid (UA), alanine aminotransferase (ALT), aspartate aminotransferase (AST), gamma glutamyltransferase (GGT), alkaline phosphatase (AP), and C-Reactive Protein (CRP). All serum analyses were performed using commercial test kits (Labtest Diagnóstica S.A. - Brazil).

Livers from all birds were collected for relative weight calculation. For histological evaluation, one fragment of each tissue (bursa of Fabricius, thymus, spleen, heart, liver, pancreas, small intestine, kidney, and lung) was collected from six birds per treatment and processed according to the usual histopathological techniques (Luna, 1968).

\section{Statistical analyses}

All data obtained were submitted to simple regression analysis. Parameters that presented significance level higher than or equal to $90 \%(p \leq 0.10)$ were submitted to analysis of variance (one-way ANOVA), and their means were compared by Bonferroni's Multiple Range Test $(p \leq 0.05)$. All statistical analyses were carried out using Statgraphics Centurion XV computer statistical program.

\section{RESULTS AND DISCUSSION}

On days 1 and 14 of the experiment, there were no differences $(p>0.05)$ in body weight or feed intake among the evaluated treatments, indicating the homogeneity required for performance evaluations.

Birds did not show any clinical signs of sLPS exposure, probably due to the low levels of sLPS applied or 
the route of administration selected. Xie et al.(2000) described some clinical signs in broilers receiving sLPS as $5.0 \mathrm{mg} / \mathrm{kg}$ of body weight (average of $3.45 \mathrm{mg} / \mathrm{bird}$ ), such as drowsiness, lethargy, and reduced feed and water intake. Those signs began within 1 hour after application of sLPS and persisted for at least four hours.

Performance results of broilers at 28 days of age are presented in Table 1. Body weight showed a significant $(P=0.05)$ but low correlation $(R=-0.17)$ with the sLPS doses used in this experiment. The comparison among treatments did not show any differences $(p>0.05)$ in body weight, feed intake, or feed conversion rate. Guaiume (2005) obtained similar broiler performance results when intraperitonially injecting 0,200 , or 400 $\mu \mathrm{g}$ E. coli LPS/application/bird (applications occurred every other day, from 7 to 21 days of age). However, Xie et al. (2000) observed a significant reduction in relative body weight gain 12, 24, and 48 hours post injection. Mireles et al. (2005), in a series of experiments applying E. coli LPS subcutaneously, observed body weight reduction and a worsening of feed conversion rate of broilers at $24,28,30,32$, or 34 days of age.

Table 2 and Table 3 present the results of clinical biochemistry parameters measured in the serum of broilers per treatment. Table 2 shows the results for total cholesterol $(\mathrm{mg} / \mathrm{dL})$, phosphorus $(\mathrm{mg} / \mathrm{dL}$ ), and uric acid (mg/dL) levels, whilst Table 3 shows the results for aspartate aminotransferase (U/L) and alkaline phosphatase (U/L) activities, and C-reactive protein (mg/L) levels. The levels of total cholesterol, phosphorus, uric acid, and C-reactive protein, and the activity of aspartate aminotransferase and alkaline phosphatase were significantly affected $(p \leq 0.10)$ by the levels of sLPS used in this experiment.
Total plasma protein, albumin, triglycerides, and calcium levels, and the activity of alanine aminotransferase and gamma glutamyltransferase, as well as the liver relative weight (data not shown) were not influenced ( $p>0.10$ ) by the evaluated sLPS levels.

Total cholesterol $(R=0.43)$ and phosphorus $(R=0.53)$ levels significantly $(p<0.01)$ increased in the presence of sLPS, whilst uric acid levels $(R=-0.38)$ significantly $(p<0.01) \quad$ decreased. Aspartate aminotransferase activity $(R=0.39)$ also significantly $(p<0.01)$ increased with sLPS inoculation.

Hypercholesterolemia and hypouricemia are commonly associated with liver damage, hyperphosphatemia with kidney damage, and increased AST activity with both liver and kidney damage (Hochleithner, 1994). According to Harr (2002), most of the synthesis of uric acid occurs in the liver, and reduced serum levels of this metabolite suggest liver damage. Concomitant exposure to LPS reduced the capacity of the liver to metabolize substances that have their primary target at this organ. It is established that the co-administration of chlorpromazine, ethionine, deoxynivalenol, monocrotaline (Roth et al., 1997), or aflatoxin B (Roth et al., 1997; Barton et al., 2000; Luyendyk et al., 2002) with small doses of LPS makes non-hepatotoxic doses of those substances potentially hepatotoxic, suggesting that some of the systemic effects of LPS are due to hepatic injury.

Xie et al. (2000) observed similar behavior of phosphorus levels in broilers receiving SLPS, and attributed this result to some transient impairment of kidney function during the acute phase of inflammatory reaction.

Table 1 - Performance of male broilers inoculated with Salmonella typhimurium lipopolysaccharide (sLPS), every other day, from 15 to 27 days of age.

\begin{tabular}{|c|c|c|c|c|c|c|}
\hline SLPS1 & $\mathrm{BW}^{2}$ & $(C V)^{3}$ & $\mathrm{Fl}^{4}$ & $(\mathrm{CV})$ & $\mathrm{FCR}^{5}$ & $(\mathrm{CV})$ \\
\hline 0 & $1,450.1^{a}$ & $(7.5)$ & $2,375.8^{a}$ & (3.1) & $1.64^{a}$ & (3.4) \\
\hline 250 & $1,422.0^{\mathrm{a}}$ & $(9.4)$ & $2,379.5^{\mathrm{a}}$ & $(2.2)$ & $1.67^{\mathrm{a}}$ & $(2.7)$ \\
\hline 500 & $1,395.7^{a}$ & $(10.7)$ & $2,326.3^{a}$ & $(3.4)$ & $1.66^{a}$ & $(1.9)$ \\
\hline $\mathrm{p}_{\text {anova }}$ & 0,14 & & 0.37 & & 0.57 & \\
\hline \multicolumn{7}{|c|}{ Correlation Matrix } \\
\hline Model & $B W=1,445$ & & \multirow[t]{2}{*}{$\mathrm{NS}^{6}$} & & \multirow[t]{2}{*}{ NS } & \\
\hline $\mathrm{R}$ & -0.17 & & & & & \\
\hline$p$ & 0.05 & & 0.23 & & 0.49 & \\
\hline
\end{tabular}

${ }^{a}$ Means in the same column with common superscript are not different by Bonferroni's test $(p \leq 0.05)$.

' $\mathrm{sLPS}=$ Dose of Salmonella typhimurium lipopolysaccharide applied to each bird, every other day, from 15 to 27 days of age ( $\mu \mathrm{g} / \mathrm{application/bird).}$

2 Body weight $(\mathrm{g})$.

${ }^{3}$ Coefficient of variation (\%)

${ }^{4}$ Cumulative feed intake ( $\left.\mathrm{g} / \mathrm{bird}\right)$

${ }^{5}$ Feed conversion ratio $(\mathrm{g} / \mathrm{g})$.

${ }^{6}$ Not significant in simple regression analysis $(p>0.10)$. 
Table 2 - Total cholesterol, phosphorus, and uric acid serum levels of male broilers inoculated with Salmonella typhimurium lipopolysaccharide (sLPS), every other day, from 15 to 27 days of age.

\begin{tabular}{|c|c|c|c|c|c|c|}
\hline SLPS' & $\mathrm{CHOL}^{2}$ & $(C V)^{3}$ & $\mathrm{P}^{4}$ & $(\mathrm{CV})$ & $\cup A^{5}$ & $(\mathrm{CV})$ \\
\hline 0 & $115.25^{b}$ & $(12.7)$ & $11.59^{b}$ & $(15.7)$ & $7.33^{a}$ & $(27.2)$ \\
\hline 250 & $123.91^{\mathrm{ab}}$ & $(17.8)$ & $13.40^{\mathrm{a}}$ & $(12.2)$ & $6.92^{\mathrm{ab}}$ & $(14.4)$ \\
\hline 500 & $136.38^{\mathrm{a}}$ & $(13.1)$ & $14.52^{\mathrm{a}}$ & $(16.6)$ & $5.88^{\mathrm{b}}$ & $(19.0)$ \\
\hline$p_{\text {anova }}$ & 0.01 & & $<0.01$ & & 0.03 & \\
\hline \multicolumn{7}{|c|}{ Correlation Matrix } \\
\hline Model & \multicolumn{2}{|c|}{$\mathrm{COL}=114.66+0.042 * \mathrm{LPS}$} & \multicolumn{2}{|c|}{$P=11.70+0.006 *$ LPS } & \multicolumn{2}{|c|}{$U A=7.43-0.003 *$ LPS } \\
\hline $\mathrm{R}$ & \multicolumn{2}{|l|}{0.43} & \multicolumn{2}{|l|}{0.53} & \multicolumn{2}{|l|}{-0.38} \\
\hline$p$ & \multicolumn{2}{|l|}{$<0.01$} & & \multicolumn{2}{|l|}{$<0.01$} \\
\hline
\end{tabular}

${ }^{a-b}$ Means in the same column with different superscripts are different by Bonferroni's test $(p \leq 0.05)$.

${ }^{1}$ sLPS= Dose of Salmonella typhimurium lipopolysaccharide applied to each bird, every other day, from 15 to 27 days of age ( $\mu \mathrm{gg} / \mathrm{application/bird).}$

2 Mean cholesterol serum levels (mg/dL).

${ }^{3}$ Coefficient of variation (\%).

${ }^{4}$ Mean phosphorus serum levels (mg/dL).

${ }^{5}$ Mean uric acid serum levels (mg/dL)

There is little information on the reduction of AP activity; however, increased AP activity in avian species has been associated with increased cellular activity (rather than cell damage) predominantly in the duodenum and kidney, indicating that decreased activity of this enzyme can be related to reduced cellular activity, either in the small intestine or in the kidney (Hochleithner, 1994).

The levels of CRP $(R=0.68)$ significantly $(p<0.01)$ increased with sLPS doses. CRP is an acute-phase protein in inflammatory responses and it is stimulated by the presence of both interleucine-1 (IL-1) and interleucine-6 (IL-6) (Tizard, 2008). It is associated with various inflammatory conditions as a positive acute-phase protein and plays an important role in the protection against infections, clearance of damaged tissue, prevention of autoimmunity, and regulation of inflammatory responses (Chamanza et al., 1999; Juul-Madsen et al., 2008). After entering the cell, LPS induces particularly, the production and secretion of IL-1, IL-6, and tumor necrosis factor (TNF $\alpha$ ). The main cells involved in the production and secretion of those cytokines are macrophages, neutrophils, and endothelial cells (Fernandes, 2005; Tuin, 2007; Liebers et al., 2008). The observed increase in CRP levels in this experiment demonstrates that LPS is one of the most powerful activators of the immune system.

At histological evaluation, no lesions were found in any tissue of the birds of the control group. In birds receiving SLPS, only the liver and the kidney were affected. Microscopic kidney changes consisted of necrosis of the tubular epithelium and were more pronounced in birds receiving $500 \mu \mathrm{g}$ sLPS, indicating a dose-response behavior. Alterations observed in the liver were hepatocellular vacuolization, hyperplasia of biliary ducts, hepatocellular degeneration, proliferation of biliary ducts, and lymphoid hyperplasia, and the severity of these lesions appeared to be the same in birds receiving either 250 or $500 \mu \mathrm{g}$ sLPS. Barton et al. (2000) also showed microscopic changes in the liver of rats receiving LPS.

Table 3 - Aspartate aminotransferase, alkaline phosphatase, and C-reactive protein serum levels of male broilers inoculated with Salmonella typhimurium lipopolysaccharide (sLPS), every other day, from 15 to 27 days of age.

\begin{tabular}{|c|c|c|c|c|c|c|}
\hline SLPS1 & $\mathrm{AST}^{2}$ & $(C V)^{3}$ & $\mathrm{AP}^{4}$ & $(\mathrm{CV})$ & $\mathrm{CRP}^{5}$ & $(\mathrm{CV})$ \\
\hline 0 & $248.92^{b}$ & $(15.7)$ & $2,756.58^{a}$ & $(22.7)$ & $144.0^{\mathrm{b}}$ & (35.6) \\
\hline 250 & $297.80^{a}$ & $(11.7)$ & $2,066.17^{\mathrm{ab}}$ & (44.9) & $163.2^{b}$ & $(28.4)$ \\
\hline 500 & $294.79^{a}$ & $(17.9)$ & $1,872.00^{b}$ & $(47.5)$ & $312.0^{\mathrm{a}}$ & (31.4) \\
\hline$p_{\text {anova }}$ & $<0.01$ & & 0.02 & & $<0.01$ & \\
\hline \multicolumn{7}{|c|}{ Correlation Matrix } \\
\hline Model & \multicolumn{2}{|c|}{ AST $=257.7+0.091 *$ LPS } & \multicolumn{2}{|c|}{$A P=2,659-1.735 * L P S$} & \multicolumn{2}{|c|}{$C R P=119.1+0.34 * L P S$} \\
\hline $\mathrm{R}$ & \multicolumn{2}{|l|}{0.39} & \multicolumn{2}{|l|}{-0.39} & \multicolumn{2}{|l|}{0.68} \\
\hline$p$ & \multicolumn{2}{|l|}{$<0.01$} & $<0.01$ & & \multicolumn{2}{|l|}{$<0.01$} \\
\hline \multicolumn{7}{|c|}{$\begin{array}{l}{ }^{1} \mathrm{~s} L P S=\text { Dose of Salmonella typhimurium lipopolysaccharide applied to each bird, every other day, from } 15 \text { to } 27 \text { days of age ( } \mu \text { g/application/bird). } \\
{ }^{2} \text { Mean aspartate aminotransferase activity in the serum (U/L). } \\
{ }^{3} \text { Coefficient of variation (\%). }\end{array}$} \\
\hline
\end{tabular}


Rauber RH, Perlin VJ, Fin CD,

Mallmann AL, Miranda DP,

Giacomini LZ, Nascimento VP do

\section{CONCLUSIONS}

The results of the present study demonstrate the impact of Salmonella typhimurium lipopolysaccharide on broilers. Despite the lack of statistical differences in performance among treatments, the presence of SLPS was significantly and negatively correlated with body weight at 28 days of age. Clinical biochemistry and inflammatory parameters were affected by the presence of SLPS, demonstrating the biological effect of this substance. As LPS is widely disseminated in poultry houses, some losses in broiler production may be currently overlooked due to a lack of understanding of the impact of LPS on broilers.

\section{REFERENCES}

Barton CC, Hill DA, Yee SB, Barton EX, Ganey PE, Roth RA. Bacterial lipopolysaccharide exposure augments aflatoxin B1-induced liver injury. Toxicological Sciences 2000;55:444-452

Chamanza R, Veen L, Tivapasi MT, Toussaint MJM. Acute phase proteins in the domestic fowl. World's Poultry Science Journal 1999:55:61-71.

Fernandes FC. Endotoxinas em aviários. Revista Brasileira de Medicina do Trabalho. 2005;3(1):22-28.

Guaiume EA. Effects of continuous administration of low-dose of Escherichia coli lipopolysaccharide in chicks and poults fed non toxic doses of aflatoxin B1 and T-2 toxin [tesis]. Columbia (MO): University of Missouri; 2005. 200 p.

Harr KE. Clinical chemistry of companion avian species: a review. Veterinary Clinical Pathology 2002;31(3):140-151.
Interference of Salmonella typhimurium Lipopolysaccharide on Performance and Biological Parameters of Broiler Chickens

Hochleithner M. Biochemistries. In: Ritchie BW, Harrison GJ, Harrison LR editor. Avian medicine and surgery: principles and applications. Lake Worth: Wingers Publishing; 1994. p.223-245.

Juul-Madsen HR, Viertlboeck B, Smith AL, Göbel TWF. Avian innate immune responses. In: Davison F, Kaspers B, Schat KA, editor. Avian Immunology. San Diego: Elsevier; 2008. p.129-158.

Liebers V, Raulf-Heimsoth M, Brüning T. Health effects due to endotoxin inhalation (review). Archives Of Toxicology 2008;82:203-210.

Luna GC. Manual of histologic staining methods of the armed forces. $3^{\text {rd }}$ ed. New York: Mc Graw-Hill; 1968.

Luyendyk JP, Shores KC, Ganey PE, Roth RA. Bacterial lipopolysaccharide exposure alters aflatoxin B1 hepatotoxicity: Benchmark dose analysis for markers of liver injury. Toxicological Sciences 2002;68:220-225.

Mireles AJ, Kim SM, Klasing KC. An acute inflammatory response alters bone homeostasis, body composition, and the humoral immune response of broiler chickens. Poultry Science 2005;84:553-560.

Mueller M, Lindner B, Kusumoto S, Fukase K, Schromm AB, Seydel U. Aggregates are the biologically active units of endotoxin. The Journa of Biological Chemistry 2004; 279:26307-26313

Nationa Research Council. Nutrient requirement of poultry. $9^{\text {th }}$ rev. ed Washington: National. Academies Press; 1994.

Roth RA, Harkema JR, Pestka JP, Ganey PE. Is exposure to Bacterial Endotoxin a Determinant of Susceptibility to intoxication from xenobiotic agents? Toxicology and Applied Pharmacology 1997; 147:300-311.

Tizard IR. Imunologia veterinária. 8 ed. Rio de Janeiro: Elsevier; 2008.

Tuin A. Detoxification of LPS by alkaline phosphatase: application of a new concept in sepsis and inflammatory bowel disease [tesis] Groningen (NL): University of Groningen; 2007. 192 p.

Xie H, Rath NC, Huff WE, Balog JM. Effects of Salmonella Typhimuruim lipopolysaccharide on broiler chickens. Poultry Science 2000;79:33-40. 